\title{
Transition to marriage and parenthood among youth in Rajasthan
}

International Institute for Population Sciences (IIPS)

Population Council

Follow this and additional works at: https://knowledgecommons.popcouncil.org/departments_sbsr-pgy

Part of the Demography, Population, and Ecology Commons, Family, Life Course, and Society Commons, International Public Health Commons, and the Medicine and Health Commons How does access to this work benefit you? Let us know!

\section{Recommended Citation}

International Institute for Population Sciences (IIPS) and Population Council. 2009. "Transition to marriage and parenthood among youth in Rajasthan," Youth in India: Situation and Needs Policy Brief no. 22. Mumbai: IIPS. 


\section{Transition to marriage and parenthood among youth in Rajasthan}

Delaying the transition to marriage and parenthood among young people has been a policy and programme priority for several years in India. For example, several national level policies formulated since 2000, including the National Population Policy 2000, ${ }^{\text {a }}$ the National Youth Policy $2003^{\mathrm{b}}$ and the National Adolescent Reproductive and Sexual Health Strategy ${ }^{c}$ have advocated special programme attention to delay age at marriage and age at first birth.

Despite these commitments, substantial proportions of girls continue to marry in adolescence in India. As recently as in 2005-2006, more than two-fifths (47\%) of women aged 20-24 were married by 18 years nationally. ${ }^{\mathrm{d}}$ Likewise, over one-fifth $(22 \%)$ of women aged 20-24 had given birth before age 18 and two-fifths (42\%) before age 20 . While the magnitude of early marriage and childbearing has been widely documented, far less is known about the extent to which young people are involved in planning their marriage, how prepared they are for married life and the nature of their married life.

This policy brief documents the magnitude of early marriage and early childbearing in Rajasthan and sheds light on young people's involvement in marriage-related planning and preparedness for married life, and the nature of married life.

The study

Data are drawn from the Youth in India: Situation and Needs study, a sub-nationally representative study undertaken for the first time in India of key transitions experienced by young people in six states of India. The study included a representative survey of young people in both rural and urban settings. Respondents included unmarried women and men and married women aged 15-24 and, in view of the paucity of married men in these ages, married men aged 15-29.
In Rajasthan, the survey was conducted in 2007. A total of 10,002 married and unmarried young men and women were interviewed in the survey. These included 1,886 married young men, 2,129 unmarried young men, 2,603 married young women and 3,384 unmarried young women. This brief is based on data obtained from the sample of married young men and women.

Child marriage continues to mark the lives of young women and men

Youth Study findings underscore that child marriage continues to characterise the lives of young women and men in the state. Of those aged 20-24, one-quarter of young women $(24 \%)$ were married before age 15 , three-fifths (60\%) before age 18 and four-fifths $(80 \%)$ before age 20 . Young women in rural areas were almost three times as likely as urban young women to be married before age 15 (29\% compared to $10 \%)$ and almost twice as likely to be married before age 18 (69\% compared to $36 \%)$.

Even though early marriage was less prevalent among young men than young women, almost one-fifth (18\%) of young men aged 20-24 years was married before age 18 and over one-third (36\%) before age 20 . Young men in rural areas were three times as likely as their urban counterparts to have married before age 18 , and twice as likely to have married before age 20 . Indeed, as many as $46 \%$ of young men aged $21-24$ were married before the legal minimum age at marriage of 21 , ranging from $25 \%$ among those in urban areas to $55 \%$ among those in rural areas.

Of note is the striking difference in the proportion of young people married before the legal minimum age at marriage by years of schooling completed by young women and men. Almost eight in ten young women with no formal schooling were married before age 18 .

Age at marriage: percentage of young women and men aged 20-24 who were married before selected ages

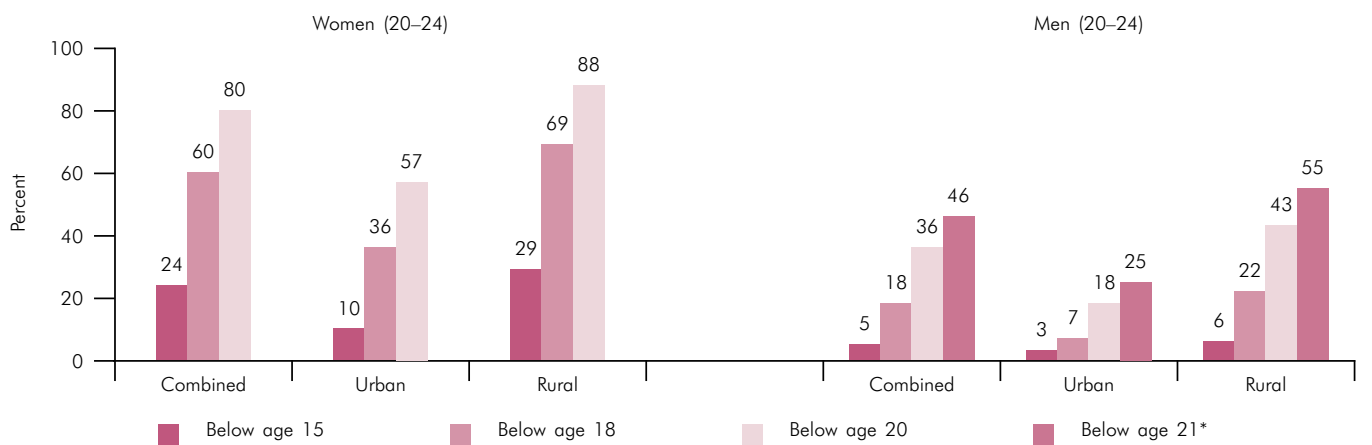

*Among those aged 21-24.

a Ministry of Health and Family Welfare. 2000. National Population Policy 2000. New Delhi: Government of India.

b Ministry of Youth Affairs and Sports. 2003. National Youth Policy 2003. New Delhi: Government of India.

${ }^{c}$ Ministry of Health and Family Welfare. 2006. Implementation Guide on RCH II: Adolescent Reproductive Sexual Health Strategy for State and District Programme Managers. New Delhi: Government of India.

d International Institute for Population Sciences (IIPS) and Macro International. 2007. National Family Health Survey (NFHS-3), 2005-06: India, Volume 1. Mumbai: IIPS. 
Percentage of young women aged 20-24 who were married before the legal minimum age at marriage, according to years of schooling, religion and caste

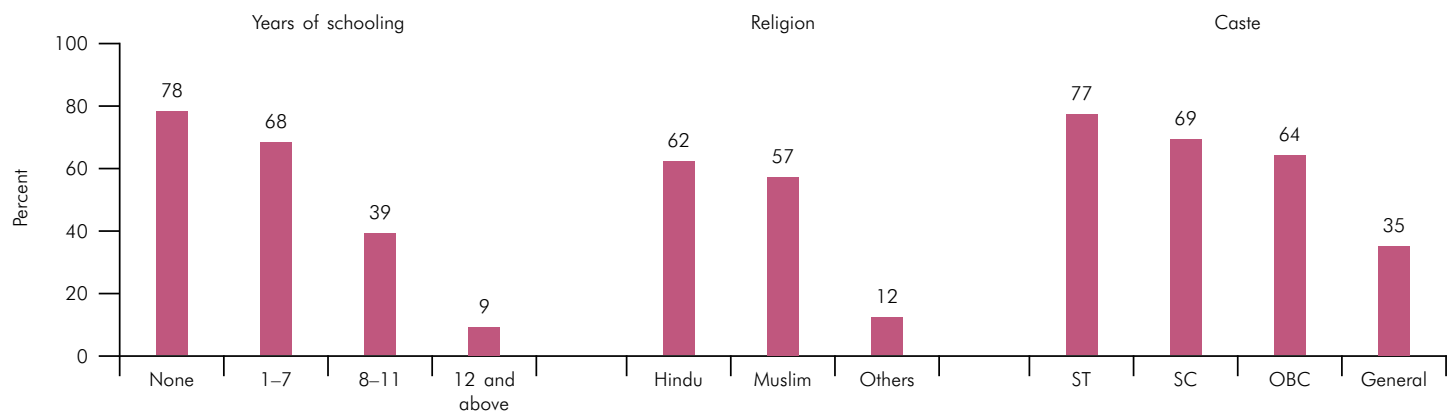

Percentage of young men aged 21-24 who were married before the legal minimum age at marriage, according to years of schooling, religion and caste

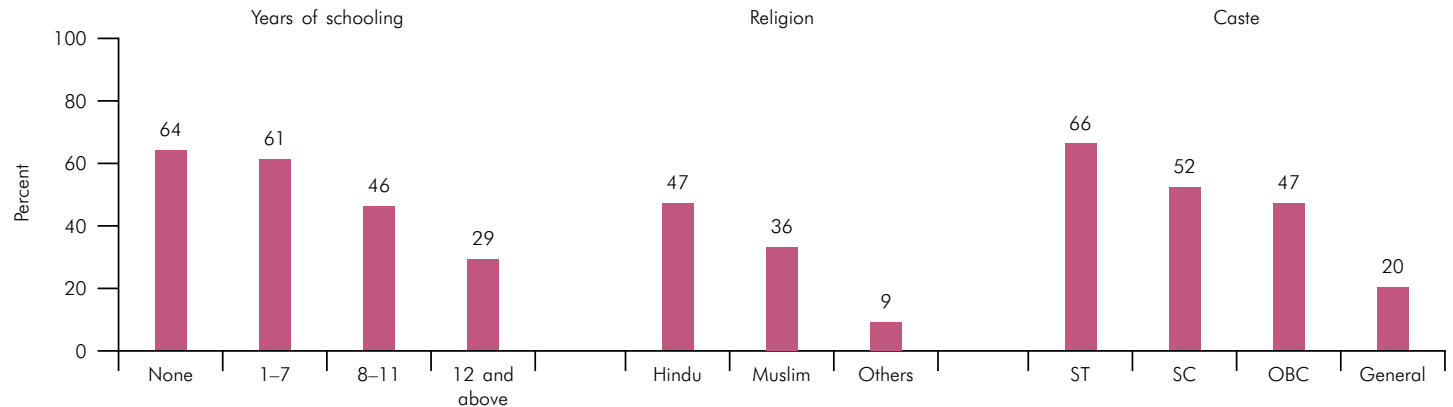

The proportion of young women married before the legal age declined to $39 \%$ among those who had some secondary education and $9 \%$ among those who had completed at least 12 years of schooling. Among young men, the proportion marrying before the legal age declined from $61-64 \%$ among those with no formal schooling or 1-7 years of schooling to $29 \%$ among those who had completed at least 12 years of schooling.

Differences by religion suggest that Muslim young women were mildly less likely than Hindu young women to have married below the legal age of 18 (57\% versus 62\%); Muslim young men, however, were considerably less likely than Hindu young men to have married below the legal age of 21 (36\% versus $47 \%$ ). Among both young men and women, those belonging to other religions were far less likely to have married below the legal age (9\% and 12\% among young men and women, respectively). Caste-wise differences suggest that young women and men belonging to general castes were much less likely, and those belonging to scheduled tribes much more likely, than others to have married before the legal age.

Young people are rarely consulted in planning their marriage

Although marriage is a key marker of young people's transition to adulthood, Youth Study findings highlight that young people were rarely consulted in planning their marriage. One in six married young men (17\%) and one in ten married young women $(11 \%)$ reported that their parents had consulted them on the timing of their marriage.

With respect to selection of spouse too, young people's involvement was limited. Almost all youth (99.5\%), whether male or female, had married a partner chosen
Young people's involvement in planning their marriage

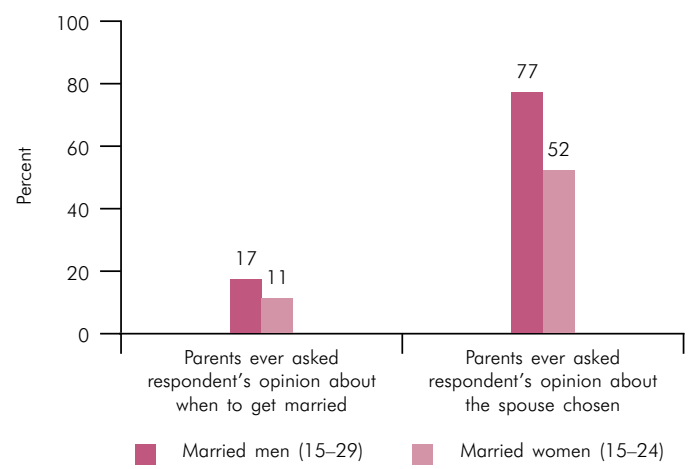

by their parents. While three-quarters of married young men $(77 \%)$ reported that their parents had sought their approval while determining their wife-to-be, young women fared much worse; just half of married young women $(52 \%)$ reported that their parents had sought their approval while determining their husband-to-be so. Indeed, as many as $22 \%$ of young men and almost half- $47 \%$ - of young women reported that their parents had not sought their approval at all.

Few young people have opportunities to get to know their spouse-to-be before marriage

Just one in ten married young men and women reported that they had ever had a chance to meet and interact with their spouse-to-be alone prior to marriage. Indeed, as many as $85 \%$ of young men and $79 \%$ of young women reported that they had met their spouse for the first time on the wedding day. Moreover, just one-quarter of young men $(26 \%)$ and one-third of young women $(33 \%)$ reported that they were aware at the time of their marriage of what to expect of 
married life, and almost two out of every five young women in both rural and urban settings (and 4\% of young men) reported that they had been scared about getting married.

Communication between spouses is limited Findings suggest that spousal communication, even on such topics as spending money, number of children they would like to have and contraception, was not universal. In total, $89 \%$ of both young men and women reported regularly discussing how to spend money and 76-82\% reported having ever discussed whether and when to have a baby. Discussion was somewhat more limited on the topic of contraception, and notably, fewer young men $(42 \%)$ than women (57\%) reported that they had ever discussed contraception with their spouse.

Spousal communication: Percentage of married young men and women who discussed various issues with their spouse

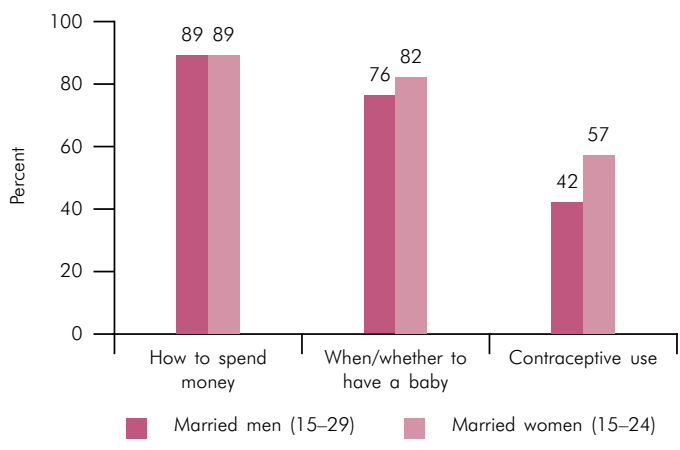

Marital life is marked by considerable violence Findings highlight that marital life was marked by considerable violence, both physical and sexual. Almost one in five married young women (18\%) reported the experience of some form of physical violence within marriage. Slightly fewer married young men-14\%-reported the perpetration of physical violence on their wife. For $7 \%$ of married young women, the experience of physical violence took place within the first year of marriage itself, and a similar proportion of married young men $(6 \%)$ reported perpetrating physical violence within the first year of marriage.

Far more young women reported having experienced sexual violence than physical violence within marriage. Over the course of their marital lives, two in five young women reported the experience of forced sex within marriage, and one-third of them had experienced forced sex at initiation itself. In contrast, married young men were considerably less likely to admit perpetrating violence on their wife: just $17 \%$ reported that they had ever perpetrated forced sex within marriage and 14\% reported that they had done so the first time sexual relations were experienced.

Contraceptive use within marriage is limited Youth Study findings indicate that the practice of contraception at any time during marital life was limited among young people in the state. For example, $38 \%$ of young men, and $24 \%$ of young women
Violence within marriage: percentage of married young women who experienced violence perpetrated by their husband

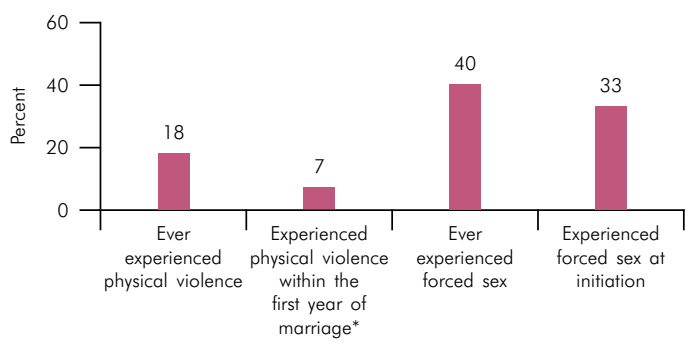

*Of those who had cohabited with their husband for at least 12 months.

Violence within marriage: percentage of married young men who perpetrated violence on their wife

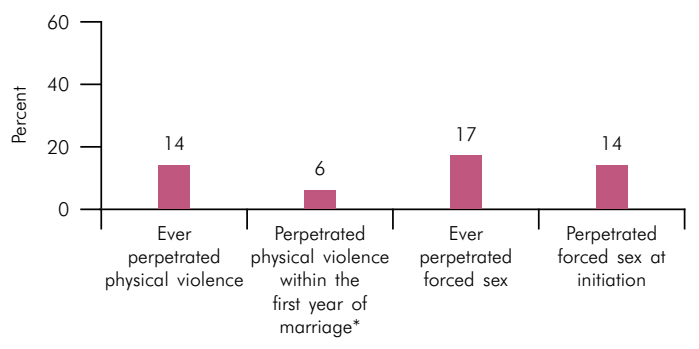

*Of those who had cohabited with their wife for at least 12 months.

reported ever use of contraceptive methods. Almost three-quarters of young men and over half of young women who had practised contraception reported having used a condom; the regularity of condom use was not probed, however, and therefore, this finding should be interpreted with caution.

At the time of the interview, just one-third of young men and one-sixth of young women were practising contraception. Findings, moreover, indicate that the practice of contraception to delay the first pregnancy was reported by one-fifth of young men, but only $8 \%$ of young women.

\section{Contraceptive practices: percentage of married young men and women who reported use of contraceptive methods}

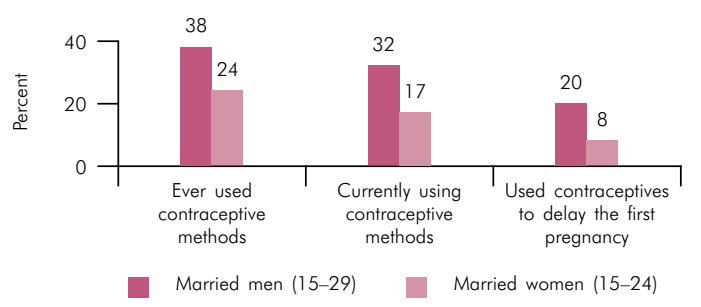

Given that more married young men than women reported the practice of contraception, it is not surprising that $8 \%$ of young men whose wife had ever became pregnant and almost one-quarter of young women who had ever became pregnant reported that their last pregnancy was mistimed or unwanted.

Childbearing in adolescence is extremely common The pressure to prove fertility as soon as possible after marriage is experienced by considerable proportions of married youth and childbearing in adolescence is 
extremely common in the state. Among married young women aged 18 or above who were cohabiting with their husband at the time of the interview, two-fifths (40\%) had their first pregnancy before age 18. Among married young men who were cohabiting with their wife and whose wife was aged 18 or above, almost two-fifths (37\%) reported that their wife had her first pregnancy before age 18 .

Utilisation of maternal health services is limited Findings suggest that despite the early age at first pregnancy, utilisation of maternal health services by young women was limited. For example, just 39-45\% of youth reported that the first-often the most risky-delivery took place in a health care facility. Although the situation was far better in urban than rural areas, just $65 \%$ of young women in urban areas had experienced their first delivery in a health facility and almost as many young men $(63 \%)$ young men reported that their wife's first delivery had taken place in a health facility. Skilled attendance at first delivery was also limited, reported by just $61-63 \%$ of young men and women.

\section{Programme recommendations}

While child marriage is particularly evident among young women, it is notable that in Rajasthan, significant proportions of young men too have married below the legal minimum age at marriage for males. Findings call for multi-pronged efforts to eliminate the practice of early marriage among young men and women, and support newly-wed young women.

\section{Mobilise communities to eliminate the practice of early marriage}

Strategies are needed that mobilise communities to help parents resist pressures that foster the practice of early marriage, and to establish new norms and practices with regard to marriage. Community mobilisation efforts must involve youth themselves, their families, as well as influential persons in the community, including religious and political leaders.

\section{Enforce existing laws on the age at marriage and} the registration of marriages

Equally important is to ensure greater commitment on the part of law enforcement agencies to enforce existing laws on the minimum age at marriage and the registration of marriages, and to levy penalties on violators. Allowing anonymous reporting, making law enforcement agencies and others aware that the practice of early marriage is not a minor violation, and making the guidelines for penalties clear to enforcement agencies and the wider community are possible steps in this direction.

\section{Provide girls with viable alternatives to early marriage}

Efforts to delay marriage also require providing girls with viable alternatives to early marriage in the form of accessible and quality schooling, and opportunities to build and use livelihood skills. Working with the education sector to make schooling for girls more accessible, and to make classrooms gender-sensitive and responsive to the needs of girls and the concerns of their parents is important. At the same time, it is necessary to provide livelihood training within and outside the educational system and to provide those out-of-school a second chance at education.

\section{Work with parents}

Parents must be apprised of the need to involve children in marriage-related decisions and enable them to interact with their prospective spouse prior to the wedding day. Evidence that many young women approached marriage with fear, and that many youth reported that they were unprepared for their marriage calls for parents to ensure that their children are appropriately informed and counselled prior to marriage. Parents must also be made aware of the fact that early marriage compromises young women's lives and reproductive health and choices in multiple ways.

\section{Support newly-weds to postpone the first pregnancy and promote pregnancy-related care among first-time pregnant young women}

Programmes are needed that inform youth about their pregnancy postponement options and enable them to access appropriate contraception. At the same time, providers must be trained and given the responsibility of reaching married young women and men-including those who have not yet experienced pregnancy-with information regarding contraception and other reproductive health matters as well as contraceptive supplies.

Findings, moreover, highlight that reproductive and child health programmes in the state need to build a demand for, as well as improve the availability of, maternal health services among young people.

\section{Address the social vulnerability of newly-wed} young women

Findings on the multiple vulnerabilities faced by young women who were married early underscore the need for programmes that support newly-wed young women, acknowledging that their situation and needs may differ from those of married adults. Efforts are needed that address the empowerment needs of married young women, enable young women to have greater control over resources, break down the social isolation they experience and encourage couple communication, negotiation and conflict management skills early in marriage.

There exist many policies and programmes-be they related to women and child development, youth or health and family welfare-that have recognised the importance of preventing early marriage and improving sexual and reproductive health and choice among young people, and that have widely acknowledged the special vulnerabilities of young women. What is needed now is ensuring that programmes in Rajasthan do indeed reach young people and the influential adults in their lives, and that promising lessons are assimilated and scaled up. 